\title{
Research of Construction Plan for Computer Basics Personalized Intelligent MOOCs Resources
}

\author{
Jin Ling \\ Jiangxi University of Technology
}

Keywords: MOOCs; Personalization; Intelligentization; Data Mining

\begin{abstract}
This article makes analysis of the problems in the learning resources organization of current computer basics MOOCs and puts forward the idea of constructing MOOCs resources by using the form of "module- network". At the same time, the plan for studying personalized MOOCs is made for learners in a bid to raise the basic application ability of learners to obtain learning resources by using computers and to improve the development education personalization and intelligentization.
\end{abstract}

\section{Brief Introduction of MOOCs}

MOOCs refers to the massive open online courses from which learning resources can be accessed free of charge by using network freedom without the limits on learners' number and school roll. The core is social learning, which is a new type of learning with main activities such as connection, communication, sharing and innovation based on the internet.

In 2011, Sebastian Thrun, a professor in Stanford University, USA, uploaded the course Introduction to Artificial Intelligence onto the internet, absorbing more than 160,000 learners from more than 190 countries, 20,000 of which finished the course, and opening the chapter of MOOCs. Thereafter, Stanford University, Harvard University, etc. joined MOOCs gradually. Up to now, three famous MOOCs resources (Coursera, Udacity, and Edx) have been approved by people from all circles of life, such as colleges and universities, foundations, enterprises, etc.

In April 2013, www.OpenupED.eu for MOOCs, launched by 11 countries in Europe, was accessed to the internet. As the first MOOCs planned in Pan-European, OpenupEd.eu provided approximately 40 courses with different subjects in 12 different languages free of charge.

In June 2013, at the first plenary meeting of Professional Teaching Guide Committee for Education Technologies and Methods, Pei Gang, president of Tongji University, recommended that MOOCs should be incorporated into the work of the Committee and that localized practice be launched from two aspects of cross-registration and cooperation among many colleges and universities. At the beginning of July, in the forum of online education development held by Shanghai Jiaotong University, 12 colleges and universities, including Beijing University, Tsinghua University, Fudan University, Shanghai Jiaotong University. etc., declared to jointly create an "online open courses" sharing platform, which indicated the founding of a real localized MOOCs consortium.

At present, famous computer basics MOOCs resources in China are the Computer Basics provided by Guokr.com (MOOC College) and lectured by Liu Yue, a teacher of National University of Defense Technology, and Fundamentals of College Computer provided by iCourse (MOOC of University of China) lectured by Gong Peizeng, a professor of Tongji University. The MOOCs 
resources mainly cover the introduction of key and difficult points, the design of teaching contents, evaluation, etc. The resources mainly include video operation, exercises and assignments, teaching case tests, drills, problems commonly met in practice, student-made work, etc.

These resources have the following problems in organization form and adaptability: (1) Resources are organized using traditional textbooks, so the contents are too fragmented and lack systematical organization and no systematical structure is formed. (2) Due to lack of personalized and intelligent design in these resources, students cannot study at their personalized study will but learn by following the prescribed order according to the resources. For the above problems, this article optimizes design mode and re-organize contents using the form of "module-network" to avoid scattered and incomplete disadvantages, pays attention to the leaners' study experience, embeds a large number of emulation, operation and exchange, and provides the learners with more quality personalized and intelligent study demands by using data mining.

\section{Construction Plan for Computer Basics MOOCs Resources}

Due to dispersed receivers of MOOCs, great difference in the foundation and study objects of learners, and more limit on study time, a computer basics course system is established by using "module-network" knowledge points to provide learners with a flexible convenient multi-threaded study mode, which is an important aspect for MOOCs construction.

Anant Agarwal, president of Edx and George Simmons, a scholar found during MOOCs teaching practice that after courses, communication among learns didn't stop, but discussed commonly interested subjects and created study groups and communities through various kinds of social media such as Second Life, Google, facebook, etc. to communicate and exchange what they had learned. Therefore, to establish a sustainable study community with interaction that can be carried out between teachers and students and among students, students can be enabled to actively take part in interaction, which has become a necessary condition to improve MOOCs study effect.

Based on the two important reasons, this article establishes MOOCs teaching resources for computer basics in three aspects: establishing teaching MOOCs resources, focusing on personalized and intelligent resources, and improving resource interaction, etc.

Establishing MOOCs resources in the form of "module-network". The idea for establishing teaching MOOCs resources is a course design idea taking learns as the center, and courses are designed on the basis of the study behavior route of learners. The teaching MOOCs resources are used in the following forms: videos, micro classes, and different modules on the internet such as special discussion areas, after-class exercise areas, interaction areas between teachers and students, online message etc. And there are reading and assignments to be finished after each class. A deadline to finish assignments is set generally. The learners can finish course assignments on time according to the plan. The assessment of assignment scores can be made via online auto scoring, self-scoring, mutual judgment among learners, etc. Most of all, teachers should connect such modularized course contents together seamlessly to form a smooth and through associated network. Only in this way can MOOCs resources not be independently divided video learning resources and excises, but are web-like learning ways. In these ways, different activities are set and not disconnected from each other in a clear bid to lead learners to deepen study actively step by step.

Establishing personalized and intelligent MOOCs resources. All learning behaviors of learners are learned by using systematical data mining technology and machines. Finding and digging hidden laws from combined macro and micro analysis so as to make teachers grasp the study conditions of 
each learners at all times, provide timely feedback, recommend learning resources, and forecast according to system feedback the teaching contents and forms (including contents difficulties, and the form and sequence of learning links) required for learners in the next step, also can continuously improve the design of course teaching contents and links, thus achieving the personalized education development object, and breaking through the bottleneck of traditional classes and forming a real intelligent teaching system.

The specific implementation process is shown in the following figure:

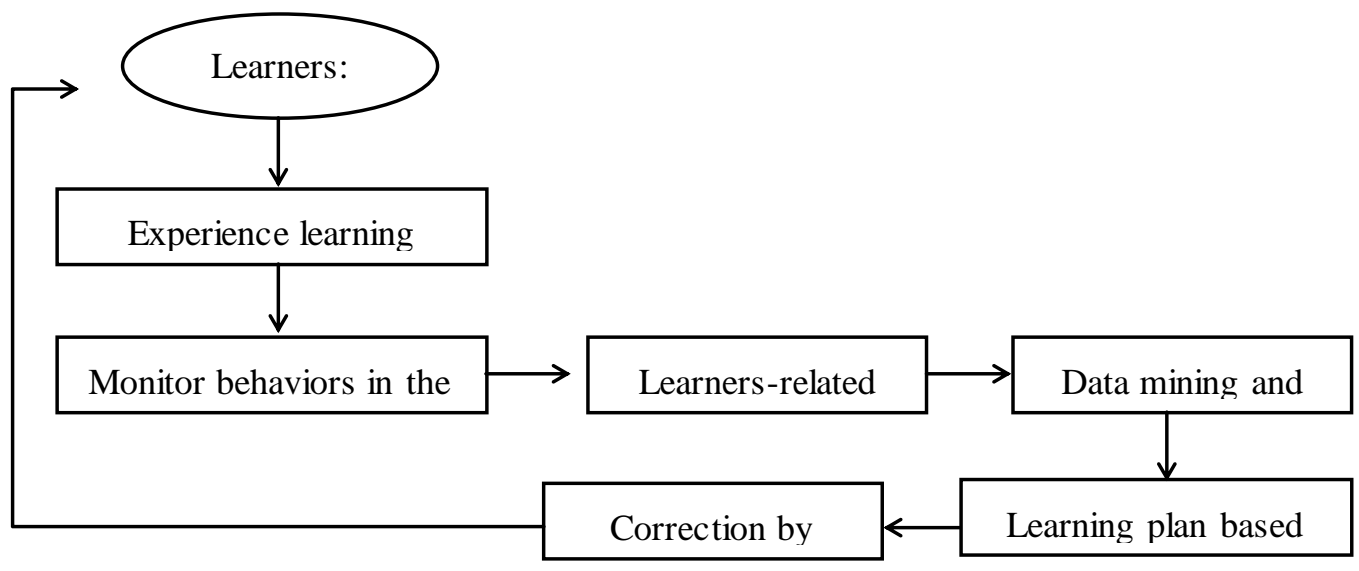

Fig. 1 Intelligent Resources System

Firstly, learners learn courses according to the teaching consents and forms designed preliminarily. During the learning process, the system will automatically monitor and measure the learning behaviors of the learner and produce mass data. After that, the system will, according to existing data mining result, classify the features of the learner and automatically put forward the adjustment plan for corresponding course contents and teaching link sequence by using a forecasting model. Teachers and researchers can interfere with the students having difficulties on the basis of data mining result and learning analysis. So to speak, this is an intelligent resources system based on teaching design and taking learners as the center.

Establishing interactive MOOCs resources. There are three methods to establish interactive MOOCs resources: (1) Create situations and encourage learners to take part in learning; Associate with learners' experience, remove the loneliness of the learners during their online study and stimulate their learning motivation through creating and simulating learning situations; (2) Organize a diversified learning community and help learners to find like-minded and knowledge-compensated learning partners in combination of the discussion habit, will and heterogeneity of learners; (3) Introduce game rules, organize and enhance interaction among learners and the activities which learners take part in, including common activities such as exchange, discussion, resources sharing, the social network of social media for teachers and students, questioning and answering, making breakthroughs and competitions, evaluation and reflection (mutual evaluation among students and teachers), in order to cohere the reflection, experience and intelligence of organizational members.

\section{Conclusions}

The explosive development of MOOCs brings new hope and subversive force to the higher education reform in the new century; however, the research of MOOCs in China just begins, so how to effectively operate MOOCs resources and carry out effective teaching are still to be groped 
continuously.

The article puts forward the methods for establishing personalized intelligent MOOCs teaching resources and hopes to improve the teaching ability of teachers at the age of MOOCs in an all-round manner; and summarizes learners' features and provides learners with personalized intelligent teaching contents and forms by using data analysis, thus realizing individualized teaching and personalized development.

The construction of MOOCs resources also needs constant study and perfection, especially some new problems to be met in specific practices. These need to be studied and perfected by vast educators and technicians constantly, in order to push forward the reform of teaching in colleges and universities.

\section{Acknowledgements}

The article is supported by Fundamentals of College Computer, an excellent course in Jiangxi and Construction of Computer Basics Personalized Intelligent MOOCs Teaching Resources (subject No.JY1419), a research subject of education and teaching reform at college level of Jiangxi University of Technology, and the research results of the excellent course, Fundamentals of Computers in Jiangxi.

\section{References}

[1] Wang Ying, Zhang Jinlei, Zhang Baohui, Analysis and Revelation of Typ ical Project Features of MOOCs [J], Remote Education, 2013(4): P 67-69.

[2] Ma Guogang, Revelation of Remote Training Development by MOOCs [J], Petroleum Education, 2013(05): P4-8.

[3] Zhang Yu, Li Yue, Learning Analysis and Education Measurement Introduction Based on MOOCs Mass Data [J], Tsinghua Journal of Education, 2013(04): P22-25.

[4] Hu Qintai, Lin Xiaofan, Research on Application Mode and Optimal Design of MOOCs Oriented to Social Education[J], E-education Research, 2014(11): P30-36.

[5] Liu Hao, Reflections on MOOCs Construction of Colleges and Universities in China [J], Laboratory Research and Exploration, 2014(12): P246-249.

[6] Zhang Yu, Li Yue, Learning Analysis and Education Measurement Introduction Based on MOOCs Mass Data [J], Tsinghua Journal of Education 2013(08): P22-26 .

[7] Liu Yang, Huang Zhenzhong, Zhang Yu, Li Manli, Research Report on Participation of Chinese Learners in MOOCs [J], Tsinghua Journal of Education, 2013(08): P27-34.

[8] Gu Xiaoqing, Hu Yiling, Cai Huiying, Localized Appeal of MOOCs [J], Distance Education Journal, 2013(05): P3-11.

[9] Zheng Jun, Wang Yining, Wang Kailing, Bai Yu. The research of the design of micro video for learning [J], China Educational Technology, 2013( 02) : P10- 13.

[10] Zhang Jinlei, Wang Ying, Zhang Baohui. Introducing a new teaching model: Flipped classroom[J], Journal of Distance Education, 2012 (04) : P46-51. 